\title{
movimento
}

faculdade de educação - programa de pós-graduação em educação

universidade federal fluminense

issn 2359-3296

ano 3 número 5 - 2016

\section{RELAÇÃO PÚBLICO-PRIVADO NA EDUCAÇÃO BÁSICA: a democratização da educação?}

Vera Maria Vidal Peroni ${ }^{1}$

\section{RESUMO}

O artigo trata das redefinições no papel do Estado, que reorganizam as fronteiras entre o público e privado e materializam-se das mais diferentes formas na educação básica pública, e suas implicações para o processo de democratização da educação. No caso brasileiro, muito lutamos no período de abertura política pela democratização com direitos sociais materializados em políticas. Mas, ao mesmo tempo em que avançamos nos direitos conquistados, também foi naturalizado que o Estado não seria mais o principal executor.

Palavras-chave: parceria público-privada em educação; política educacional; democratização da educação.

\section{ABSTRACT}

The article deals with the redefinitions of the role of the state, which reorganize the boundaries between public and private that materialize in many different forms in basic public education, and their implications for the process of democratization of education. In the Brazilian case, we have struggled so hard since the so-called 'opening period' of political democratization with social rights materialized in public policies. However, while we have advanced in the conquered rights, at the same time the idea of the State as the main provider no longer prevails.

Keywords: public-private partnership in education; educational policy; democratization of education

\section{Introdução}

\footnotetext{
1 Doutora, professora UFRGS, veraperoni@gmail.com
} 
Este artigo procura debater as mudanças ocorridas nas relações entre o público e o privado, neste período particular do capitalismo, de redefinições do papel do Estado $^{2}$ e as implicações para a democratização da educação neste contexto.

As mudanças nas fronteiras entre o público e o privado têm se modificado neste período de crise do capitalismo, em que as suas estratégias de superação neoliberalismo, globalização, reestruturação produtiva e Terceira Via - redefinem o papel do Estado, principalmente para com as políticas sociais.

É importante destacar que, em nosso enfoque teórico metodológico, a política educacional não é, simplesmente, determinada pelas mudanças sociais e econômicas, mas é parte constitutiva dessas mudanças. Concordamos com Harvey (2005) que o Estado, assim como capital, deve ser visto como relação ou processo. Assim, entendemos que ele é parte importante do movimento de correlação de forças de sujeitos ${ }^{3}$ situados em um contexto histórico e geográfico ${ }^{4}$. Portanto, Estado e sociedade civil são perpassados por correlações de forças de classes sociais e projetos societários distintos. Destacamos que estamos tratando em nossas pesquisas da sociedade civil mercantil, onde o privado está vinculado ao mercado. O foco da análise é a privatização do público, na lógica mercantil, com implicações para a democratização da educação.

Nesse sentido, não se trata de uma contraposição entre Estado e sociedade civil, pois vivemos ainda em uma sociedade de classes em que sociedade civil e Estado são perpassados por interesses mercantis.

É importante, ainda, ressaltar que a relação entre o público e o privado não inicia neste período particular do capitalismo; historicamente, foram muito tênues as linhas divisórias entre o público e o privado em nosso país. Assim, a

\footnotetext{
2 Estado é aqui entendido como Estado histórico, concreto, de classe, e, nesse sentido, Estado máximo para o capital, já que, no processo de correlação de forças em curso, é o capital que detém a hegemonia.

${ }^{3}$ Sujeitos individuais ou coletivos na concepção de Thompson (1981).

${ }^{4}$ Contexto histórico e geográfico na concepção de Harvey (2005)
} 
democratização da educação pública ainda é um longo caminho e questionamos acerca das implicações da mercantilização do público neste processo.

O conceito de democracia que embasa as análises é a não-separação entre o econômico e o político, com direitos sociais materializados em políticas (WOOD, 2003) e a coletivização das decisões (VIEIRA, 1998) com a elaboração de políticas na prática social, crítica e autocrítica no curso de seu desenvolvimento (MÉSZÁROS, 2002). Enfim, a democracia não é uma abstração, é a materialização de direitos em políticas coletivamente construídas na autocrítica da prática social (PERONI, 2013)

No enfoque teórico metodológico que embasa nossas pesquisas ${ }^{5}$, buscamos entender como se materializa a relação entre o público e o privado na educação, neste período particular do capitalismo, analisando o objeto de estudo em suas múltiplas relações, enquanto movimento, que se materializa na realidade social com muitas contradições, através de sujeitos com processos societários distintos, em uma relação de classe e não como estruturas estáticas. ${ }^{6}$

Lukács nos ajuda a caminhar nesta difícil perspectiva de análise, quando enfatiza a importância do conceito de relação neste processo: "O singular não existe senão em sua relação com o universal. $O$ universal só existe no singular, através do singular" (LUKÁCS, 1978, p. 109). E também quando enfatiza a importância do particular como mediação na análise: "O movimento do singular ao universal e vice-versa é sempre mediatizado pelo particular, ele é um membro intermediário real, tanto na realidade objetiva quanto no pensamento que a reflete de um modo aproximadamente adequado" (LUKÁCS, 1978, p. 112). Assim, entendemos o objeto de estudo, a relação entre o público e o privado na educação, como parte de um contexto histórico e geográfico particular, com contradições, e uma história de lutas pela democratização da educação materializada em direitos.

\footnotetext{
${ }^{5}$ Pesquisa atual "Implicações da relação público-privada para a democratização da educação", financiada pelo CNPq e realizada pelo Grupo de Pesquisa: Relações entre o Público e o Privado na Educação, vinculado ao Núcleo de Política e Gestão da Educação do Programa de Pós-Graduação em Educação da Universidade Federal do Rio Grande do Sul.

${ }^{6}$ Conforme Thompson $(1989,2012)$.
} 
Também buscamos a categoria analítica do particular no sentido de entender as especificidades deste período particular do capitalismo, que conserva questões estruturantes do capitalismo, mas tem particularidades que o definem também. Não entendemos que seja um pós-capitalismo, mas capitalismo com características específicas, particulares, no sentido de que mantém a relação com o universal e materializam o universal com as características e correlações de forças do seu tempo histórico. (Peroni, 2015)

\section{As redefinições do papel do Estado}

Entendemos as redefinições no papel do Estado como parte de mudanças sociais e econômicas deste período particular ${ }^{7}$ de crise estrutural do capital, em que as contradições estão mais acirradas. Meszaros (2011) adverte para a importância de adequada avaliação da natureza da crise econômica e social. Para o autor, "a crise do capital que estamos experimentando é uma crise estrutural que tudo abrange" (MÉSZÁROS, 2011, p. 2). Para Antunes (1999), a crise do Fordismo e do Keynesianismo foi a expressão fenomênica de um quadro crítico mais complexo de tendência decrescente da taxa de lucros, e com o "desencadeamento da sua crise estrutural começava também a desmoronar o mecanismo de regulação que vigorou durante o pós guerra, em vários países capitalistas avançados, especialmente na Europa" (ANTUNES, 1999, p. 31).

O Estado foi chamado historicamente a tentar controlar ou regular as contradições do capital e a relação capital/trabalho. Atualmente, apesar do anunciado Estado mínimo pelo neoliberalismo, ele é chamado a "socorrer" o capital produtivo e financeiro nos momentos de maior crise. $E$,

\footnotetext{
7 Particular na concepção de Lukács (1978) "O movimento do singular ao universal e vice-versa é sempre mediatizado pelo particular; ele é um membro intermediário real, tanto na realidade objetiva quanto no pensamento que a reflete de um modo aproximadamente adequado." (LUKÁCS, 1978, p. 112)
} 
contraditoriamente, foi e é considerado o "culpado pela crise" pela teoria neoliberal (PERONI, 2013a).

Assim como no pós-guerra suas estratégias foram principalmente o fordismo/ Keynesianismo, nos países centrais, e o fordismo/Estado desenvolvimentista nos países periféricos, neste período suas principais estratégias são o neoliberalismo, a reestruturação produtiva, a globalização e a Terceira Via.

O capital necessita de uma ideologia ${ }^{8}$ para construir a ambiência cultural ${ }^{9}$ necessária a este período particular do capitalismo, camuflado de póscapitalismo. Da mesma forma que o fordismo dependia de um sistema geral de regulamentação por parte do Estado, chegando a ser visto menos como um mero sistema de produção em massa do que como um modo de vida total, também este momento histórico, com suas especificidades no âmbito do modo de produção, necessita de uma ideologia para que tais particularidades sejam aceitas e incorporadas (PERONI, 2003).

Para Mészáros (1996), a propaganda ideológica serve para camuflar os reais problemas da crise capitalista:

[...] ao mesmo tempo em que as contradições do mundo social se tornam mais fortes do que nunca, manifestando-se em escala cada vez mais global, são repetidamente declaradas 'superadas' ou prestes a ser 'ultrapassadas' - em uma sucessão interminável de construções ideológicas que metamorfoseiam, sob um novo rótulo 'pós', dissociado, a mesma racionalização apaziguadora, no momento mesmo em que sua versão anterior perde credibilidade (MÉSZÁROS, 1996, p.31).

Outro pressuposto teórico da análise do processo de redefinição do papel do Estado foi o de que a crise fiscal é parte de um movimento maior de crise do

\footnotetext{
8 O conceito de ideologia utilizado neste trabalho é o proposto por Mészáros (1996): "a ideologia não é ilusão nem superstição religiosa de indivíduos mal orientados, mas uma forma específica de consciência social, materialmente ancorada e sustentada. (MÉSZÁROS, 1996, p.22-3).

${ }^{9}$ Por nova ambiência cultural, entendemos a alteração na forma de vida objetiva e subjetiva para produção da subjetividade necessária ao novo período de acumulação.
} 
capital, e não a causadora da crise, como foi diagnosticado pelo neoliberalismo e pela Terceira Via.

O papel do Estado para com as políticas sociais é alterado, pois com este diagnóstico duas são as prescrições: racionalizar recursos e esvaziar o poder das instituições, já que instituições democráticas são permeáveis às pressões e demandas da população, além de serem consideradas como improdutivas, pela lógica de mercado. Assim, a responsabilidade pela execução das políticas sociais deve ser repassada para a sociedade: para os neoliberais através da privatização (mercado), e para a Terceira Via pelo público não-estatal (sem fins lucrativos) (PERONI, 2013).

Buchanan (1984), teórico neoliberal, aponta as instituições democráticas contemporâneas como irresponsáveis, e o remédio seriam medidas restritivas constitucionais para conter os governos, colocando-se os instrumentos de controle fora das instituições representativas e partindo-se do princípio de que os controles políticos são inferiores ao de mercado. Observamos, nas pesquisas acerca das parcerias entre o público e o privado, que esta tem sido uma a justificativa apontada pelas instituições privadas para fazer a parceria. Como é o caso do Instituto Ayrton Senna ${ }^{10}$, que parte do pressuposto que a educação pública vai mal e que deve "salvá-la":

Os programas do Instituto Ayrton Senna são soluções educacionais que ajudam a combater os principais problemas da educação pública do país. E contemplam três grandes áreas: educação formal, educação complementar e educação e tecnologia. (...) Implementados em grande escala com estratégias e metas pré-definidas, os programas recebem acompanhamento e avaliações sistemáticas para alcançar um único objetivo: o sucesso do aluno na escola. (grifo da autora)

(http://senna.globo.com/institutoayrtonsenna/programas/programas_educacao_fo rmal.asp acesso em 2 de fevereiro de 2014)

É interessante destacar, ainda, que o Instituto trabalha definindo políticas, com a concepção, acompanhamento e avaliação da educação nas redes públicas

\footnotetext{
10 Sobre o tema parcerias entre sistemas públicos de educação básica e o Instituto Ayrton Senna ver relatório de pesquisa Adrião, Peroni, 2010.
} 
parceiras. Na justificativa de sua atuação, apresenta problemas na qualidade de ensino e assume o que seriam tarefas do Estado para com as políticas públicas de educação.

Esta perspectiva salvacionista, de que o privado mercantil deve garantir a qualidade da educação pública, não é uma visão isolada de um Instituto, ela está inserida em uma lógica que naturaliza esta participação, pois parte do pressuposto neoliberal que não é o capitalismo que está em crise, mas o Estado. A estratégia, para esta concepção, é reformar o Estado ou diminuir sua atuação para superar a crise. O mercado é que deverá superar as falhas do Estado, portanto a lógica do mercado deve prevalecer, inclusive no Estado, para que ele possa ser mais eficiente e produtivo.

Para o pensamento neoliberal, há uma tensão entre a liberdade individual e a democracia. Conforme Hayek, a maximização da liberdade está em proteger o sistema de mercado como necessário e suficiente para a existência da liberdade. Assim, o mercado deve ser protegido contra o Estado e da tirania das maiorias. $E$ adverte que se o Estado é influenciado, ou vulnerável às influências das massas, os dois perigos se fundem.

Para essa teoria, o cidadão, através do voto, decide sobre bens que não são seus, gerando conflitos com os proprietários, já que é visto como uma forma de distribuição de renda. Hayek (1983) denuncia que a democracia faz um verdadeiro saque à propriedade alheia. $\mathrm{E}$, como em muitos casos não se pode suprimir totalmente a democracia (voto, partidos), o esforço é para esvaziar seu poder.

Para Hayek (1983), a democracia ilimitada leva à economia dirigida e está a um passo do totalitarismo. Portanto, adverte para os perigos da democracia ilimitada: "uma democracia pode empunhar poderes totalitários, e é pelo menos concebível que um governo autoritário pode atuar com base nos princípios liberais. Liberalismo é, portanto, incompatível com democracia ilimitada, (...)" (HAYEK, 1983, p. 143). 
Outra escola neoliberal, a Teoria da Eleição Pública, conhecida como Public Choice, faz uma análise econômica da política ${ }^{11}$. O ponto de partida de discussão da Escola é que a economia e a política de um país são inseparáveis. A ideia chave da Public Choice é de que o paradigma da ação humana em todas as dimensões passa pela relação de troca, pelo jogo de interesses. Isso é tanto um pressuposto como uma prescrição, no sentido de que a Escola trabalha para que todas as relações tenham a troca como modelo. (BUCHANAN et al, 1984).

Ball (2013), analisa criticamente a presença de "outros" sujeitos que assumem o protagonismo na definição de políticas educacionais com parâmetros de mercado:

[...] tarefas e serviços anteriormente realizados pelo Estado estão agora sendo feitos por vários "outros", em vários tipos de relacionamento com eles mesmos, com o Estado e com as restantes organizações mais tradicionais do setor público, embora em muitos casos o método de trabalho dessas organizações do setor público também tenham sido fundamentalmente reformulados, tipicamente pelo posicionamento estratégico de formas de mercado (competição, escolha, e financiamento baseado no desempenho). Portanto, novas vozes e interesses são representados no processo político, e novos nós de poder e influência são construídos e fortalecidos. (BALL, 2013a , p. 177)

Buchanan (1984), teórico neoliberal, critica o excesso de regulamentação e de Estado, pois julga que estas atividades são onerosas para o conjunto da sociedade e diminuem sua produtividade.

Para a Buchanan (1984), a democracia e as regulações sobre o Estado são prejudiciais ao livre andamento do mercado, por isso é preciso estabelecer limites constitucionais contra as instituições democráticas vigentes: eliminando o voto, o que é mais difícil, ou restringindo o impacto do voto através da privatização e desregulamentação, provocando o desmantelamento do Estado.

A Terceira Via é apresentada por Giddens (2001) como uma proposta alternativa ao neoliberalismo e à antiga social democracia, no entanto como tem o mesmo diagnóstico, de que a crise está no Estado, propõe o repasse das políticas

11 O seu principal teórico é James BUCHANAN, é também conhecida como Escola de Virgínia, pois se constituiu no Instituto Politécnico da Universidade de Virgínia na década de 1950. 
sociais para a sociedade civil, através de parcerias com o terceiro setor. Neste sentido, a democracia entendida como a não separação entre o econômico e o político (Wood 2003), como direitos sociais materializados em políticas universais, é substituída por outro conceito de democracia, em que participação da sociedade significa, em muitos casos, assumir a responsabilidade da execução das políticas sociais ${ }^{12}$, mais do que participar nas decisões e no controle social.

Robertson e Verger (2012) também apontam questionamentos sobre a democracia no debate acerca da relação entre o público e o privado: "parcerias e redes de regulamentação tendem a reduzir a democracia à negociação no seio da sociedade civil entre atores extremamente desiguais [...]" (ROBERTSON, VERGER, 2012, p. 1138).

caráter não governamental assumido pelo terceiro setor, que implica não ser submetido ao controle institucional, aponta uma importante questão na medida em que essas organizações têm um poder cada vez maior. Assim, surgem questões como: em nome de quem estão operando? Já que muitas vezes, estão vinculadas diretamente às agências internacionais, a quem prestam contas? Qual é o padrão ético de julgamento? Quem julga suas ações? E, se tem legitimidade, quem a outorga?

Ball (2013) ressalta a importância desse setor, o que denomina de nova filantropia:

[...] soluções inovadoras e velhas soluções para problemas sociais e de desenvolvimento 'baseadas no mercado' estão sendo privilegiadas e fortalecidas através do surgimento de uma nova elite global, conectada em rede, formada por promotores de políticas e 'novos' filantropos. O que há de 'novo' na 'nova filantropia' é a relação direta entre o 'doar' e os 'resultados' e o envolvimento direto dos doadores nas ações filantrópicas e nas comunidades de políticas. [...]

Tudo isso re-situa o escopo e os objetivos da filantropia tradicional. Isso indica uma mudança em três etapas: da doação paliativa (ou seja, a filantropia tradicional

12 Ver o caso das creches comunitárias e programas de educação de jovens e adultos no final do texto. 
ou a 'filantropia 1.0') à filantropia para o desenvolvimento ('filantropia 2.0'), e, finalmente, à doação 'rentável', constituindo aquilo que é chamado de 'filantropia 3.0'. (Ball, Olmedo, 2013, p. 33-34)

Ball e Olmedo (2013) destacam ainda que esta terceira etapa da filantropia ocorre através das redes:

A Filantropia 3.0 faz parte de uma nova configuração e lógica de ações de ajuda e desenvolvimento e de um novo conjunto de relações ligadas a problemas de desenvolvimento e aos grandes desafios. Chamamos esta lógica e relações de 'filantropia de rede'. Ao usar este termo estamos sugerindo que para entender o trabalho das 'novas' organizações filantrópicas e seus 'parceiros', precisamos considera-los não sob uma perspectiva individual, como atores isolados, mas sim como nós interconectados que operam de acordo com lógicas de rede e configuram suas agendas e ligações de formas mutantes e fluídas. (BALL, OLMEDO, 2013, p. 40)

No Brasil, verificamos o protagonismo do Movimento Todos pela Educação, criado em setembro de 2006:

O Todos Pela Educação é um movimento financiado exclusivamente pela iniciativa privada, que congrega sociedade civil organizada, educadores e gestores públicos que tem como objetivo contribuir para que o Brasil garanta a todas as crianças e jovens 0 direito à Educação Básica de qualidade. (http://www.todospelaeducacao.org.br/institucional/quem-somos acesso em 14 de abril de 2011)

É interessante observar que a estratégia de atuação engloba o monitoramento e análise dos indicadores educacionais oficiais, não apenas definindo a pauta, mas monitorando e avaliando resultados da agenda da política educacional no país.

A estrutura organizacional do Movimento Todos pela Educação é composta por um Conselho de governança, cujo presidente é Jorge Gerdal Johannpeter, conhecido empresário brasileiro, um conselho fiscal e uma equipe executiva. 
Este movimento tem um protagonismo cada vez maior, não apenas no Brasil, mas em toda a América Latina. Em setembro de 2011, organizou um seminário em conjunto com o BID (Banco Interamericano de Desenvolvimento) para a criação da rede latino-americana de organizações da sociedade civil pela educação:

\begin{abstract}
A rede foi lançada na sessão especial do Congresso Internacional: 'Educação: uma Agenda Urgente', realizado em Brasília, de 13 a 16 de setembro. O dia de trabalho do Congresso foi organizado pelo Todos Pela Educação em parceria com o Banco Interamericano de Desenvolvimento (BID). O evento contou com a participação de autoridades de diferentes países, entre elas, do ministro da Educação, Fernando Haddad. http://www.todospelaeducacao.org.br/comunicacao-emidia/noticias/18886/movimentos-criam-rede-latino-americana-de-organizacoesda-sociedade-civil-pela-educacao/
\end{abstract}

Ball (2012) destaca a importância de analisar estes movimentos através de pesquisa empírica, assim que na pesquisa atual "Parcerias entre sistemas públicos e instituições do terceiro setor: Brasil, Argentina, Portugal e Inglaterra implicações para a democratização da educação", além da interlocução teórica com grupos de pesquisa que tratam do tema, analisamos no Brasil diferentes formas de relação entre o público e privado na educação básica.

\title{
Múltiplas formas de materialização do privado na educação básica pública no Brasil
}

As redefinições no papel do Estado implicam o processo de democratização e a minimização de direitos universais e de qualidade para todos, o que traz consequências para as populações de todo o mundo; no entanto, em países que viveram ditaduras e um processo recente de luta por direitos materializados em políticas, o processo de privatização é ainda mais danoso. No Brasil, o Estado foi, historicamente, vinculado aos interesses privados (Fernandes, 1987; Vieira, 1998; Pires, 2015 e Cury, 2003). 
Após o último período de ditadura, a partir de meados dos anos 1980, entrou na pauta da sociedade, mesmo que de forma tímida, o processo de democratização, participação, coletivização das decisões, assim como direitos sociais materializados em políticas. Ao mesmo tempo, os processos de neoliberalismo, reestruturação produtiva e financeirização redefiniam o papel do Estado para com as políticas sociais, com um diagnóstico de crise fiscal e redução de custos. Assim, ocorreram avanços inegáveis no acesso à educação, no entanto, com os "recursos possíveis" e, muitas vezes, em detrimento de salários e condições de trabalho dos profissionais da educação. A ampliação de direitos pela universalização do acesso, inclusão de alunos com necessidades especiais, maior participação na vida escolar não foi seguida de condições materiais com a mesma intensidade das mudanças. (Peroni, 2016)

Vivemos a contradição de que, ao mesmo tempo em que a privatização do público é cada vez maior, também, em um processo de correlação de forças, estamos avançando lentamente em alguns direitos materializados em políticas educacionais. Trata-se de direitos que foram reivindicados no processo de democratização, nos anos 1980, e materializados em parte na Constituição Federal de 1988 e na Lei de Diretrizes e Bases (LDB) de 1996, como a gestão democrática da educação, a educação básica entendida como educação infantil, fundamental e média, a gratuidade da educação pública, entre outros. Assim, ao mesmo tempo em que ocorrem algumas conquistas sociais para a democratização da educação, em um processo de correlação de forças, verificase a organização de setores vinculados ao mercado, influenciando as políticas educativas das mais diversas formas. Nossas pesquisas demonstram que, no Brasil, o processo de privatização do público ocorre tanto através da direção como da execução, ou de ambas (Peroni, 2016).

Destacamos que, no Brasil, no ensino fundamental e médio, a oferta expandiu via escola pública e a privatização ocorreu mais no conteúdo da educação, no entanto, outras etapas da educação básica, como a educação infantil ou as modalidades de Educação de Jovens e Adultos (EJA), educação profissional, vivem outro processo em que o poder público repassa a execução da oferta 
educacional para o setor privado com ou fins lucrativos, como forma de barateamento ou racionalização de recursos.

Na educação infantil, a análise ocorreu principalmente sobre as parcerias dos sistemas públicos com creches comunitárias para a oferta de vagas para crianças. Desde que as creches foram consideradas parte da educação básica, e assim saíram da assistência social e vieram para a educação, como parte da reivindicação de pais, educadores e pesquisadores da área, o poder público municipal, que ficou responsável pela oferta desta etapa da educação básica, buscou como alternativa, em muitos casos, as parcerias com instituições sem fins lucrativos. Há uma grande preocupação da fragilidade e da precariedade deste atendimento, no que se refere às condições físicas do local, projeto pedagógico, remuneração e formação dos professores e a não gratuidade, com mensalidades $^{13}$ sendo cobradas mesmo recebendo dinheiro público e de famílias muito carentes. Outro fator importante é a ausência de gestão democrática nas instituições, com critérios pouco transparentes na admissão e pagamento dos funcionários, falta de critérios para a admissão das crianças, de prestação de contas da entidade, assim como nas relações dentro das creches e da instituição dos os pais e comunidade.

No ensino fundamental, pesquisamos o programa do governo federal PDE/PAR, (Plano de Desenvolvimento da Educação/Plano de Ações articulada) que fomenta e até financia parcerias do sistema público com instituições do terceiro setor; a compra de sistemas de ensino privados pelos sistemas públicos, interferindo assim no conteúdo e gestão da educação pública; e parcerias entre os sistemas públicos com instituições do terceiro setor, como o Instituto Ayrton, Senna, Alfa e Beto e outros de atuação nacional.

No Ensino Médio, estudamos a parceria entre o Instituto Unibanco e escolas de ensino médio. O Unibanco tem uma característica diferente e muito preocupante, ele financia a escola e, assim, muitas escolas públicas acabam aderindo para

\footnotetext{
${ }^{13}$ As instituições dizem que são contribuições, mas na maioria dos casos estudados eram mesmo que veladamente critério para a admissão e permanência de crianças, conforme relato de pais.
} 
receber recursos, e portanto submetendo-se às metas do Instituto, que interfere em toda a escola, desde o conselho escolar, até no conteúdo de ensino, já que aplicam provas e as escolas que não atingirem as metas propostas não recebem a parcelas o financiamento.

No ensino profissional vinculado ao médio, estudamos principalmente 0 atual programa proposto pelo governo federal PRONATEC (Programa Nacional de Acesso ao Ensino Técnico e Emprego) que tem entre seus objetivos a articulação entre o ensino médio e o profissional. Ressaltamos a participação de instituições privadas na execução do Programa.

Na educação especial o poder público historicamente desresponsabilizou-se da educação especial, e no momento em que estava começando a ser entendida como um direito, a nova conjuntura de racionalização de recursos dificultou a implementação com qualidade das políticas de inclusão e restringiu a ampliação de escolas públicas de educação especial. E a prática de repasses de recursos públicos que já eram destinados às instituições públicas não governamentais, como APAE, Pestalozzi, etc., para a execução de tarefas que seriam do poder público, atualmente é fortalecida pelo movimento em que o Estado retira-se ou diminui a sua atuação na execução de políticas, passando-as para a sociedade civil.

Na Educação de Jovens e Adultos pesquisamos o Programa Alfabetização Solidária (ALFASOL) e o Programa Brasil Alfabetizado. O ALFASOL teve importância enorme na simbiose entre o público e o privado durante o governo Fernando Henrique Cardoso, foi o "embrião" do público não-estatal no Brasil, já que era um programa de governo realizado por uma instituição do terceiro setor, presidido pela própria primeira-dama e recebendo dinheiro público para a sua execução. Esta instituição permanece atuante e executando muitos projetos com o governo federal. E o Programa Brasil Alfabetizado atua com bolsas e vínculos com instituições do terceiro setor para sua execução. 
Nos limites deste artigo apresentaremos dois exemplos de nossas pesquisas, que envolvem parcerias: o Instituto Ayrton Senna com escolas de ensino fundamental e o Instituto Unibanco com escolas de ensino médio.

\section{Instituto Ayrton Senna}

O IAS vincula a aprendizagem à gestão das escolas. Entende que a escola deve ter uma gestão gerencial, rigidamente monitorada e com atividades padronizadas, através de aulas prontas e uma rotina. $O$ foco deve ser na matemática e língua materna, que são as atividades avaliadas nas provas nacionais. Entende que a aprendizagem é um produto, que pode ser mensurado através os resultados das avaliações e metas pré-estabelecidas. Os programas do IAS apresentam um material com forte conteúdo prescritivo

No programa Gestão Nota Dez, os dados (notas, avaliações, presenças, metas alcançadas) são coletados pelo professor, que faz o acompanhamento individual dos alunos e repassa as informações para a direção. O diretor, por sua vez, faz um relatório consolidado dos dados, analisando-os para verificar se as metas propostas foram alcançadas pelos alunos. Esse material é enviado para a SMEC, que, então, faz outro material consolidado das escolas municipais. $O$ material é enviado ao IAS, através do Sistema Instituto Ayrton Senna de Informação (SIASI), o qual, de acordo com os resultados, manda o material específico. Assim, indicadores de sucesso, diagnósticos da realidade educacional, relatórios de acompanhamento, intervenção e avaliações de processo e de resultado pautam o trabalho técnico realizado.

O acompanhamento do trabalho dos professores dá-se por meio de visitas semanais do supervisor e de sua participação em reuniões quinzenais para avaliação, troca de experiências e planejamento junto com outros professores. Os cursos de capacitação são à distância. 
Há uma coleta diária de informações sobre a frequência de alunos e professores, de abandono dos alunos, de registro de visitas dos supervisores, de participação dos professores nas reuniões quinzenais e até do número de livros lidos pelos alunos. Esse acompanhamento constante restringe em muito a autonomia do professor.

\section{Instituto Unibanco}

O Instituto Unibanco foi criado em 1982, inicialmente para promover as ações e os investimentos sociais do banco e, não por acaso, expandiu sua atuação na educação formal em 2003, quando foi eleito o governo Lula, com a expectativa social de uma proposta de educação mais vinculada aos trabalhadores. $O$ Instituto tinha como objetivo que suas tecnologias se transformassem em políticas públicas, por isso em 2007 concebeu e implantou o Projeto Jovem de Futuro (PJF), que atuou em escolas de ensino médio, de forma experimental. Em 2011, o PJF teve sua tecnologia validada e ampliada para a aplicação em larga escala, em parceria com o Ministério da Educação, no Programa Ensino Médio Inovador (PROEMI). A parceria passou a se chamar ProEMI/JF. (INSTITUTO UNIBANCO, 2014)

Como vimos, a proposta do PROEMI tem o foco no currículo, enquanto o Instituto Unibanco, através do Programa Jovem de Futuro, apresenta uma proposta mais vinculada à gestão da escola como indutora da aprendizagem dos alunos.

O Programa Jovem de Futuro parte do diagnóstico de que o problema está na gestão da escola, considerada ineficiente e ineficaz, e propõe a Gestão Escolar para Resultados (GEpR), que adota sistemas de informação voltados para o monitoramento, controle e avaliação e a utilização de programas de comunicação para garantir ampla adesão da comunidade às ações da escola, com objetivos orientados para os resultados na aprendizagem (http://www.portalinstitutounibanco.org.br/ Acesso em 21 de maio de 2014.). Para controlar as ações do projeto Jovem de Futuro, o Instituto Unibanco desenvolveu 
uma Plataforma online de gestão de projetos das escolas e formação a distância. Atualmente, é composta pelo Sistema de Gestão de Projetos (SGP) e pelo Ambiente Virtual de Aprendizagem (AVA). É um sistema de controle muito parecido com o SIASI do Instituto Ayrton Senna.

Outro ponto de destaque é a formação de professores e gestores na gestão por resultados. É obrigatória a participação em um curso de 120 horas durante os três anos do projeto. Na escola, participam o diretor, o coordenador pedagógico e um professor, e na secretaria de educação participam supervisores e técnicos responsáveis por acompanhar as escolas, profissionais que são o centro das decisões na definição e execução das políticas educacionais. (Peroni, Caetano, 2014)

Verificamos que as parcerias entre os Instituto Unibanco (IU) e Instituto Airton Senna (IAS) com escolas públicas trabalham definindo políticas, com a concepção, acompanhamento e avaliação da educação nas redes públicas parceiras. Na justificativa de sua atuação, apresentam problemas na qualidade de ensino e assumem o que seriam tarefas do Estado para com as políticas públicas de educação. As metodologias empregadas são padronizadas e replicáveis, ao contrário das propostas de reestruturação produtiva, do próprio capital, que propõem a formação de um trabalhador criativo, que responda rapidamente às demandas com capacidade de raciocínio e trabalho em equipe. No quadro a seguir, apresentamos um exercício para ver as semelhanças e especificidades dos Institutos estudados: 
Quadro comparativo entre Instituto Ayrton Senna e Instituto Unibanco

\begin{tabular}{|c|c|c|}
\hline & IAS & IU \\
\hline Proposta de gestão & Gestão para o Sucesso & Gestão para resultados \\
\hline $\begin{array}{ll}\text { Sistema } & \mathrm{de} \\
\text { Monitoramento } & \end{array}$ & SIASI & SGP \\
\hline Material & Padronizado e replicável & Padronizado e replicável \\
\hline Equipe & \begin{tabular}{lr} 
Um & \multicolumn{2}{c}{ coordenador } \\
responsável & na \\
secretaria e outro na \\
escola, do quadro \\
funcional, mas formado \\
pelo Instituto e \\
responsável por \\
monitorar o alcance das \\
metas propostas
\end{tabular} & \begin{tabular}{ll} 
Um & \multicolumn{2}{c}{ coordenador } \\
responsável & na \\
secretaria e outro na \\
escola, do quadro \\
funcional, mas formado \\
pelo Instituto e \\
responsável por \\
monitorar o alcance das \\
metas propostas
\end{tabular} \\
\hline Estratégias & Premiação & Premiação \\
\hline Estratégias & Competitividade & Competitividade \\
\hline $\begin{array}{ll}\text { Convênios } & \text { com } \\
\text { sistemas públicos }\end{array}$ & \begin{tabular}{lr} 
Secretaria de & Assuntos \\
estratégicos & da \\
Presidência & da \\
República & (SAE), \\
Ministério da Educação, & Secretarias Estaduais e \\
\multicolumn{2}{l}{ Municipais }
\end{tabular} & \begin{tabular}{lr} 
Secretaria de & Assuntos \\
estratégicos & da \\
Presidência & da \\
República & (SAE), \\
Ministério da Educação, & Secretarias Estaduais e \\
\multicolumn{2}{l}{ Municipais }
\end{tabular} \\
\hline Ano que iniciou & 1994 & 1982 \\
\hline $\begin{array}{l}\text { Ano que iniciou atuar em } \\
\text { redes públicas }\end{array}$ & 1997 & 2007 \\
\hline $\begin{array}{l}\text { Participa do Movimento } \\
\text { Todos pela educação }\end{array}$ & Sim & Sim \\
\hline Abrangência & Nacional & Nacional \\
\hline $\begin{array}{l}\text { Etapa da educação } \\
\text { básica em que atua }\end{array}$ & $\begin{array}{lr}\begin{array}{l}\text { Historicamente } \\
\text { fundamental }\end{array} \\
\text { atualmente ensino } \\
\text { realizando um projeto- } \\
\text { piloto no RJ para } \\
\text { atuação no Ensino } \\
\text { Médio }\end{array}$ & Ensino Médio \\
\hline
\end{tabular}

Fonte: Elaboração da autora. (Peroni, 2016)

Os Institutos definem o que deve ser feito, desde o Secretário de Educação até os professores e alunos. A proposta é baseada na gestão gerencial, os dois participam do Movimento Todos pela Educação (MTE), que tem atuado decisivamente na direção das políticas educativas, trazendo a lógica de mercado para o sistema público em todos os seus níveis. Assim, atuam desde a direção 
da política através do MTE, até a sala de aula, via parcerias, onde exercem monitoramento (SIASI e SGT) e premiação e sanções introduzindo valores competitivos e meritocráticos para o sistema.

Robertson (2012) destaca ainda a influência do setor privado em todas as instâncias da educação:

Contudo, o que frisamos aqui é a maneira pela qual uma determinada concepção de educação está sendo globalizada e gerida, e que, longe de ser um mecanismo para diminuir o liberalismo econômico, aparentemente as PPPEs permitiram seu rápido avanço, dado que o setor privado está agora profundamente enraizado no coração dos serviços públicos educacionais, em todos os níveis, desde a política e a pesquisa até a aprendizagem nas salas de aula. (Robertson, 2012, p. 1149)

No caso das parcerias, verificamos que a gestão democrática fica muito prejudicada quando desde o secretário de Educação até os professores as tarefas são definidas por um agente privado. Questionamos o que significa o sistema público abrir mão de suas prerrogativas de ofertar educação pública de qualidade e comprar um produto pronto, desde o currículo escolar - já que as aulas vêm prontas e os professores não podem modificá-la - até a gestão escolar (monitorada por um agente externo), e transformar os sujeitos responsáveis pela educação em burocratas que preenchem muitos papéis. Isto, inclusive, contraria a Lei de Diretrizes e Bases da Educação Nacional (Brasil, 1996) no que se refere à gestão democrática da educação:

Art. 14. Os sistemas de ensino definirão as normas da gestão democrática do ensino público na educação básica, de acordo com as suas peculiaridades e conforme os seguintes princípios:

- participação dos profissionais da educação na elaboração do projeto pedagógico da escola;

- participação das comunidades escolar e local em conselhos escolares ou equivalentes.

Art. 15. Os sistemas de ensino assegurarão às unidades escolares públicas de educação básica que os integram progressivos graus de autonomia pedagógica e 
administrativa e de gestão financeira, observadas as normas gerais de direito financeiro público. (Brasil, 1996).

Apresentamos como exemplo o Instituto Ayrton Senna, que parte do diagnóstico de que os professores não são capazes de planejar suas tarefas e por isso devem receber tudo pronto, como podemos verificar na argumentação de Viviane Senna:

Os materiais são fortemente estruturados, de maneira a assegurar que um mesmo professor inexperiente, ou com preparação insuficiente - como é o caso de muitos professores no Brasil - seja capaz de proporcionar ao aluno um programa de qualidade, com elevado grau de participação dos alunos na sala de aula, na escola e na comunidade. (SENNA 2000, p. 146).

Como diz Viviane Senna, os conteúdos são "fortemente estruturados", o que se configura como um retrocesso na autonomia da escola e do professor, e assim, no processo de democratização da educação. Sobre esse tema, exemplificamos com a fala de uma professora entrevistada:

[...] a gente tinha uma lista de conteúdos programados que a gente tinha que seguir a risca, então quando o supervisor entrava na sala, ele olhava qual era o número do dia letivo, qual era o sub-projeto e qual era a aula, então, por exemplo, eu tinha dois dias para trabalhar o Símbolo da Páscoa, mas não interessava se os meus alunos estavam interessados em estudar mais, se eles tinham atingido os objetivos do conteúdo, eu tinha três dias para trabalhar a historia de Jesus, não interessava se meus alunos tinham atingido ou não os objetivos, se eles estavam interessados, se em um dia eu já tinha conseguido vencer o conteúdo, o que interessava é que eu tinha três dias para trabalhar aquilo e eu tinha que respeitar a regra, todas as turmas da rede de ensino, naquele dia, estavam trabalhando aquele mesmo conteúdo, e isso era, digamos assim, inquestionável. Os temas eles já vinham definidos, era obrigado, tu não debatia com o aluno o que ele queria estudar, tu tinha que a partir daquele dia, trabalhar aquela temática, e durante aquele período que tinha sido pré-definido.

$\mathrm{E}$ ai de ti se não fizesse certo. (professora do município B) 
Robertson (2012) ressalta as características das instituições privadas que realizam parcerias com o setor público:

\begin{abstract}
Essa indústria de especialistas em PPPEs é parte de novo setor de serviços de educação, que inclui um número crescente de consultores que operam globalmente, organizações de gestão de educação, bem como fundações de ensino e filantropos engajados na modelagem da prática e da política educacionais (ROBERTSON, 2012, p. 12).
\end{abstract}

A autora ressalta, ainda, que não são mudanças apenas de natureza técnica, mas atuam nas concepções e objetivos, o que temos chamado em nossas últimas pesquisas de "conteúdo da educação". Uma questão intrigante é que o material, por exemplo do IAS, é fortemente estruturado, como declarado pela própria coordenadora do Instituto Viviane Senna, o material é padronizado, assim que o mesmo material é para escolas indígenas da região amazônica ou para um município urbano em São Paulo ou Rio Grande do Sul, conforme constatamos em nossa pesquisa nacional que abrangeu dez estados brasileiros com características muito diferentes. No entanto, as exigências deste período atual do capitalismo de reestruturação produtiva, exigem um trabalhador flexível, que saiba pensar, trabalhar em equipe, exatamente o contrário do material proposto na parceria.

Concordamos com as preocupações de Robertson (2012) de que as parcerias provocam indefinições acerca das responsabilidades de quem será o responsável pelo direito à educação e quem define seus objetivos e conteúdo:

[...] quando a governança está distribuída em vários locais, tanto a governança das PPPs quanto das PPPEs, como ferramenta de gestão do setor da educação, torna-se problemática. Quem é a autoridade relevante? Quem é afetado pelas decisões de vários governos, empresas transnacionais, fundações, agências internacionais e consultores? Quem deve ser procurado para prestar contas? É o discurso gerencial apropriado para a distribuição de um bem público como a educação? A gestão, com foco em resultados e na eficiência, é compatível com a 
complexidade dos processos educacionais? (ROBERTSON, VERGER, 2012, p. 1151)

Neste artigo apresentamos alguns elementos para o debate de como as redefinições no papel do Estado reorganizam as fronteiras entre o público e privado e materializam-se das mais diferentes formas na educação básica pública, e suas implicações para o processo de democratização da educação no Brasil. Enfatizo que é na democratização da educação e não apenas na garantia do acesso, pois em muitos casos o poder público continua o responsável pelo acesso, e inclusive amplia o acesso público, mas o "conteúdo" pedagógico e de gestão da escola é determinado por instituições introduzem a lógica mercantil, com a justificativa de que assim estão contribuindo para a qualidade da escola pública. Outra questão vinculada ao papel do Estado que tratamos foi a importância das redes globais para a definição da educação. Ball (2013) trabalha com conceitos como heterarquia, governabilidade e metagovernança para apresentar sua discussão teórica acerca das redefinições no papel do Estado, que para o autor "não é um esvaziamento do Estado, antes é uma nova modalidade de poder público, agência e ação social e, na verdade uma nova forma de estado. Ou seja, a realização de fins políticos por diferentes meios [...]" (BALL, 2013, p. 180). São questões muito polêmicas que envolvem a democratização da educação, principalmente em países com pouca cultura democrática e que não tiveram políticas públicas universais e que ainda lutam pelo direito à educação, como é o caso do Brasil.

\section{Considerações Finais}

No Brasil, não temos um histórico democrático e de participação efetiva da sociedade. No período de abertura política, a sociedade começou a dar os primeiros passos nesse sentido. Mas, nos países de capitalismo avançado, a democracia e a participação eram questionadas como as responsáveis pela crise do Estado, já que para atender às demandas dos grupos organizados o Estado 
teria investido em políticas sociais, gastado demais e gerado a crise fiscal e a inflação, a democracia passa a ser combatida não mais por uma ditadura, mas no plano político e ideológico, e com a ajuda dos meios de comunicação, passase a relacionar a luta por direitos como atos contra a nação. Os culpados pela crise seriam os funcionários públicos e o investimento nas políticas sociais.

A Terceira Via não considera a democracia como inimiga, como o neoliberalismo, mas como instrumental à retirada do Estado das políticas sociais, através das parcerias com o terceiro setor. Apela-se para a subjetividade das pessoas através da ajuda mútua, da solidariedade, da filantropia, enquanto o dinheiro público dos impostos é deslocado para a esfera financeira.

Com os novos sujeitos que passam influenciar fortemente as políticas educacionais como instituições filantrópicas e redes globais, as responsabilidades ficam cada vez mais diluídas quanto a responsabilidade pela execução do direito à educação

Questionamos países em que, como o Brasil, estão iniciando o processo de construção da democracia, a privatização da educação pública traz consequências importantes, não apenas para a efetivação do direito à educação que ainda não é uma realidade para todos no país, mas também acerca do conteúdo da educação que tem o mercado com parâmetro de qualidade.

Enfim, conforme o conceito de democracia tratado neste artigo, como coletivização das decisões (VIEIRA, 1998), direitos sociais materializados em políticas (WOOD, 2003), e a elaboração de políticas através da prática social crítica e autocrítica no curso de seu desenvolvimento (MÉSZÁROS, 2002), ressaltamos que as mais diversas formas de relação entre o público e o privado materializados em políticas educacionais, tem fordes implicações para a democratização da educação. 


\section{Referências Bibliográficas}

ADRIÃO, T. \& PERONI, V.. Análise das consequências de parcerias firmadas entre municípios brasileiros e a Fundação Ayrton Senna para a oferta educacional. Relatório de pesquisa, 2010.

ANTUNES, R.. Os Sentidos do Trabalho: Ensaios sobre a afirmação e a negação do trabalho. São Paulo: Boitempo editorial, 1999.

BALL, S. Global education INC. New policy networks and the neo-liberal imaginary. London: Routledge, 2012.

BALL, S. OLMEDO. A. A "nova" filantropia, o capitalismo social e as redes de políticas globais em educação. In: PERONI, V. (org). Redefinições das fronteiras entre o público e o privado: implicações para a democratização da educação. Brasília, Liber Livro, 2013.

BRASIL. Constituição da República Federativa do Brasil de 1988. Disponível em: <http://www.planalto.gov.br/ccivil_03/constituicao/constituiçao.htm>. Acesso em: 20 dez.

2009.

BRASIL. Lei n 9.394, de 20 de dezembro de 1996. Lei de Diretrizes e Bases da Educação Nacional. Disponível em: <http://www.planalto.gov.br/ccivil_03/LEIS/I9394.htm>. Acesso em: 20 dez. 2009

BUCHANAN, J., MCCORMICK, R., TOLLISON, R. El analisis economico de lo politico: lecturas sobre la teoria de la elección publica. Madrid: Instituto de Estudios Economicos, 1984.

CURY, C. R. J.. O público e o privado no Brasil: fronteiras e perspectivas. In: OLIVEIRA, Dalila Andrade; DUARTE, Marisa R. T. Política e trabalho na escola: administração dos sistemas públicos de educação básica. Belo Horizonte: Autêntica, p. 123-128, 2003.

FERNANDES, F.. A Revolução burguesa no Brasil, 3. ed. Rio de Janeiro: editora Guanabara, 1987.

GIDDENS, A. A. Terceira Via: reflexões sobre o impasse político atual e o futuro da social-democracia. Rio de Janeiro: Record, 2001.

HAYEK, F. O caminho da servidão. Rio de Janeiro: Livraria O Globo, 1983.

HARVEY, D. O neoliberalismo história e implicações. São Paulo: Loyola, 2005. 
INSTITUTO UNIBANCO. O Plano em Ação: circuito de gestão contínuo, integrado e com foco nos resultados de aprendizagem. São Paulo: Instituto Unibanco, 2014.

LUKÁCS, G., Introdução a uma estética marxista. Rio de Janeiro: Civilização Brasileira, 1978.

MÉSZAROS, I. O poder da Ideologia. São Paulo: Ensaio, 1996.

MÉSZAROS, I. Para além do Capital. São Paulo: Boitempo Editorial, Campinas: Editora da UNICAMP, 2002, 2011.

PERONI, V. M. V. Política educacional e papel do Estado no Brasil dos anos 90. São Paulo: Xamã, 2003.

PERONI, V. M.V. A. A gestão democrática da educação em tempos de parceria entre o público e o privado. Pro-Posições, Campinas, v. 23, n. 2, ago. 2012.Disponível em <http://www.scielo.br/scielo.php?script=sci_arttext\&pid=S010373072012000200003\&lng=pt\&nrm=iso>.

PERONI, V. (org.). Redefinições das fronteiras entre o público e o privado: implicações para a democratização da educação. Brasília, Liber Livro, 2013.

PERONI, V. M. V. As Relações entre o Público e o Privado nas Políticas Educacionais no Contexto da Terceira Via. Currículo sem Fronteiras Privatização da educação no contexto da(s) "Terceira(s) Via(s)": uma caracterização em análise. v. 13 - n. 2 - maio/agosto, 2013a.

PERONI, V. M. V. Implicações da relação público-privada para a democratização da educação no Brasil. In: PERONI, Vera (Org.). Diálogos sobre as redefinições no papel do Estado e nas fronteiras entre o público e o privado na educação. São Leopoldo: Oikos, 2015.

PERONI, V. M. V. As Implicações da relação público-privada para a democratização da educação no Brasil. Tese (promoção a Professor Titular da Carreira do Magistério Superior), UFRGS. 2016. Disponível em https://plone.ufrgs.br/gprppe

PERONI V. \& CAETANO, R. Relações entre o público e o privado na educação: Projeto Jovem de Futuro do Instituto Unibanco. Trabalho apresentado na ANPAE Sudeste, 2014.

PIRES, D. de O. A construção histórica da relação público-privada na promoção do direito à educação no Brasil. 2015. 264 f. Tese (Doutorado em Educação) Programa de Pós-Graduação em Educação, Faculdade de Educação, Universidade Federal do Rio Grande do Sul, Porto Alegre, 2015. 
ROBERTSON, S., MUNDY, K., VERGER, A. MENASHY. Public Private partnerships in Education new actors and modes of governance in a globalizing world. Edward London: Elgar Publishing limited, 2012.

ROBERTSON, S. A estranha morte da privatização neoliberal. Revista Brasileira de Educação. ANPED. V. 17, n.50 maio ago 2012 São Paulo: Autores Associados, 2012a.

ROBERTSON, S., VERGER, A. A origem das parcerias público-privada na governança global da educação. Educ. Soc., Dez 2012, vol.33, no.121, p.11331156. ISSN 0101-7330. 2012.

SENNA, V. O Programa Acelera Brasil. In: Em aberto. vol.17, n.71. Brasília: Ministério da Educação/Instituto Nacional de Pesquisa Educacionais, 2000.

THOMPSON, E. P. A miséria da teoria ou um planetário de erros. Rio de Janeiro: Zahar, 1981.

VIEIRA. E. O Estado e a sociedade civil perante o ECA e a LOAS. Serviço Social \& Sociedade, São Paulo, n. 56, p. 9-23, mar, 1998.

WOOD, E. M. Democracia contra o capitalismo a renovação do materialismo histórico. São Paulo: Boitempo Editorial, 2003.

Entrevista:

Professora do município B [Entrevista]. 2007. Entrevista concedida a Juliana Lumertz e Daniela Dinis em 11 de setembro de 2007, na Secretaria Municipal de Educação, Arquivos de Pesquisa, Porto Alegre. 